\title{
A New Assessment Method of new Energy in Regional Sustainable Development based on Hesitant Fuzzy Information
}

\author{
Hongdi Yao, Wenxing Li \\ School of Economics and Management, Beijing Jiaotong University, China \\ 07113098@bjtu.edu.cn,wxli@bjtu.edu.cn
}

Received: October 2014

Accepted: November 2014

\section{Abstract:}

Purpose: The new energy has been an important driving force in region sustainable development. It is a critical issue to evaluate the role of new energy in region sustainable development.

Design/methodology/approach: To deal with this issue, this paper proposes a new score function, in which, both mean and variance are considered. Then it introduces the basic operators, such as hesitant fuzzy weighted averaging operator and hesitant fuzzy weighted geometric operator to get the comprehensive assessment provided by the decision maker on each attribute.

Findings: Due to the drawbacks of existing methods with hesitant fuzzy information, this paper puts forward a method and the procedure to solve the MADM (multiple attribute decision making) problem. And an illustrative example is demonstrated to verify the reliability of the proposed method.

Research limitations/implications: The method can be used to evaluate the new energy in regional sustainable development, but it cannot solve the problems with many experts.

Practical implications: Based on the new framework, a case study is carried out to verify its applicability and validity. The research can fill the gaps for the assessment framework of new 
energy in regional sustainable development. This paper is of practical value in real life, which is the application of some techniques.

Originality/value: This paper describes in detail in evaluating the role of new energy in region sustainable development. And a new score function is proposed with hesitant fuzzy information, that is, the idea of variance is introduced to form a new score function to measure the deviation of hesitant fuzzy elements. Meanwhile, the basic operator, such as hesitant fuzzy weighted averaging operator and hesitant fuzzy weighted geometric operator are introduced to integrate the hesitant fuzzy information.

Keywords: evaluation framework, new energy, sustainable development, hesitant fuzzy information

\section{Introduction}

With the rapid development of global economy, environmental issue has gradually been highlighted. To deal with the contradiction between economy development and environmental protection, the opinion of sustainable development has become the global cognition (Singh, Murty, Gupta \& Dikshit, 2009). Energy is the basis of economic and social development. Most of energy is for the provision of lighting, heating, cooling, and air conditioning (Omer, 2008). There has several energy crises sine 1970s and the world economy had been seriously affected. Much of the world's energy is currently produced and consumed in ways that could not be sustainable (Bilgen, Keles, Kaygusuz, Sari \& Kaygusuz, 2008). Increasing awareness of the environmental impact of $\mathrm{CO} 2$ emissions triggered a interest in environmentally friendly new energy. Therefore, more and more researchers had been interest in the development of new energy, especially the role of new energy in sustainable development(Krupa \& Burch,2001; Valochi, Juliano \& Schurr, 2014; Hawila, Mondal, Kennedy \& Mezher, 2014).

Sahir and Qureshi (2008) presented a review of the assessed potential of new and renewable energy (such as solar, wind and biomass resources) and practical limitations to their significant use, in the context of present scenarios and future projections of the national energy mix for Pakistan. Evans, Strezon and Evans (2009) proposed new assessment technologies of sustainable indicators for new and renewable energy. The key indicators of sustainability used in the assessment included: price of electricity generation, greenhouse gas emissions, availability and technological limitations, efficiency of energy generation, land use, water consumption and social impacts. Kemmler and Spreng (2007) proposed energy-based indicators which were quite relevant for social issues. The three energy measures are primary, useful, and an access-adjusted useful energy, all of which are used for the analysis of comparison. Afgan, Garrera and other researchers also paid their attention to assessment of 
new energy in sustainable development (Afgan \& Carvalho, 2008; Carrera \& Mack, 2010; Pang, Mortberg \& Brown, 2014).

Based on literatures mentioned above, the most studies presented some indicators about new energy or sustainable development. However, there are few assessment framework related to fuzzy information. In real life, it is difficult to express the decision maker's preferences accurately in most situations. The preferences provided by the decision maker usually result in uncertain, imprecise, and subjective data (Dubois \& Prade, 1985). Fuzzy logic and fuzzy set are suitable to hand imperfect, vague or imprecise information (Zimmermann, 1985). Due to the advantages of fuzzy sets in terms of expressing human preferences, Zadeh (1965) presented the basic model of fuzzy sets based on the theory of fuzzy mathematics, which had been successfully used for handling fuzzy decision making problems. Recently, some researchers found it is sometimes difficult to determine the membership and non-membership of an element into a fixed set and which may be caused by a doubt among a set of different values. Therefore, Torra and Narukawa (2009)defined hesitant fuzzy sets (HFSs) to deal with decision making problems, which permits the membership of an element to a set presented as several possible values between 0 and 1 . Since the basic concepts on HFSs were defined by Torra, HFS had been widely investigated (Torra, 2010; Xu \& Zhang, 2013; Wei, 2012).

In this paper, motivated by the literatures mentioned above, it proposes a new assessment framework to evaluate region sustainable development, in which the new energy is as the driving force. This framework is developed with hesitant fuzzy information. In addition, the assessment framework is considered as multiple attribute decision making (MADM) framework. Although HFS is popularly used in many assessment framework, there are some deficiencies in existing methods with HFSs. For example, the mostly score functions used in hesitant fuzzy sets, especially mean of possible membership degrees (Xia \& Xu, 2011), cannot effectively solve the difference among possible membership degrees. To deal with this problem, this paper proposes a new score function, in which both mean and variance are considered. So the paper introduces the basic operators, such as hesitant fuzzy weighted averaging operator and hesitant fuzzy weighted geometric operator to get the comprehensive assessment provided by the decision maker on each attribute. Finally, a case study is carried out to verify the applicability and validity of the new framework.

The rest of this paper is organized as follows. In Section 2, it reviews some basic concepts related to hesitant fuzzy sets. Section 3 it introduces the new assessment framework with hesitant fuzzy information. In Section 4, a case study is carried out to demonstrate the proposed method, and its validity and applicability. Finally, Section 5 conclusions. 


\section{The Standard Algorithm}

Definition 1. (Tora \& Narukawa, 2009; Torra, 2010). Let $X$ be a universe of discourse, then a HFS $E$ over $X$ is defined as

$$
E=\left\{<x, h_{E}(x)>\mid x \in X\right\},
$$

where $h_{E}(x)$ symbolizes possible membership degrees of $x$ to $\mathrm{E}$, each of which is limited to $[0,1]$.

In hesitant fuzzy sets, the length of the membership of $M$ denoted by $l\left(h_{M}\left(x_{i}\right)\right)$ does not mostly equal to that of $\mathrm{N}$ denoted by $l\left(h_{N}\left(x_{i}\right)\right)$. To solve this problem, $\mathrm{Xu}$ and Xia (2011)suggested that it should extend the shorter one depending on the decision maker's risk preferences until both of them have the same length. Optimists expect desirable results and the maximum value should be added, while pessimists anticipate unfavorable outcomes and the minimal value should be added. The decision maker preference is risk-neutral, so Xu and Xia (2011) developed a new method to overcome the drawback of previous algorithm according to the decision maker's all risk preference (Xu and Zhang, 2013). An extension value $\bar{h}=\eta h^{+}+(1-\eta) h^{-}(0 \leq \eta \leq$ 1 ) is introduced to gain the final decision results. The parameter $\eta$ can reflect the decision maker's risk preference more accurately. If $\eta=1$, it indicates that the DM's risk preference be risk-seeking; if $\eta=0$, it indicates that the decision maker's risk preference be risk-averse; if $\eta=$ 0.5 , it indicates that the decision maker's risk preference be risk-neutral.

Definition 2. Given three HFNs denoted by $h, h_{1}$ and $h_{2}$, their basic operations are defined as:

$$
\begin{gathered}
h^{c}=\bigcup_{\gamma \in h}\{1-\gamma\} ; \\
h_{1} \cup h_{2}=\bigcup_{\gamma_{1} \in h_{1}, \gamma_{2} \in h_{2}} \max \left\{\gamma_{1}, \gamma_{2}\right\} ; \\
h_{1} \cap h_{2}=\bigcup_{\gamma_{1} \in h_{1}, \gamma_{2} \in h_{2}} \min \left\{\gamma_{1}, \gamma_{2}\right\} .
\end{gathered}
$$

Here, $h^{\mathrm{c}}$ represents the complement of the HFN $h$.

Definition 3. Given three HFNs denoted by $h, h_{1}$ and $h_{2}$, their new basic operations are defined by Xia and Xu as follows:

$$
\begin{gathered}
h_{\lambda}=\bigcup_{\gamma \in h}\left\{\gamma^{\lambda}\right\} ; \\
\lambda h=\bigcup_{\gamma \in h}\left\{1-(1-\gamma)^{\lambda}\right\} ;
\end{gathered}
$$




$$
\begin{gathered}
h_{1} \oplus h_{2}=\bigcup_{\gamma_{1} \in h_{1}, \gamma_{2} \in h_{2}}\left\{\gamma_{1}+\gamma_{2}-\gamma_{1} \gamma_{2}\right\} ; \\
h_{1} \otimes h_{2}=\bigcup_{\gamma_{1} \in h_{1}, \gamma_{2} \in h_{2}}\left\{\gamma_{1} \gamma_{2}\right\} .
\end{gathered}
$$

Based on these operations, Xia and Xu (2013) proposed a series of aggregation operators with hesitant fuzzy information.

Definition 4. Let $h_{j}(j=1,2, \ldots, n)$ be a collection of HFSs. A hesitant fuzzy weighted averaging (HFWA) operator is a mapping $H_{n} \rightarrow H$ such that:

$$
\operatorname{HFWA}\left(h_{1}, h_{2}, \ldots, h_{\mathrm{n}}\right)=\bigoplus_{j=1}^{n}\left(w_{j} h_{j}\right)=\bigcup_{\gamma_{1} \in h_{1}, \gamma_{2} \in h_{2}, \ldots, \gamma_{n} \in h_{n}}\left\{1-\prod_{j=1}^{n}\left(1-\gamma_{j}\right)^{w_{j}}\right\},
$$

where $w=(w 1, w 2, \ldots, w n)^{\top}$ is the weight vector of $h_{j}(j=1,2, \ldots, n)$ with $0 \leq w_{j} \leq 1(j=1,2$, $\ldots, n)$ and $\sum_{i=1}^{n} w_{j}=1$.

When $w=(1 / n, 1 / n, \ldots, 1 / n)^{\top}$, the HFWA operator reduces to the hesitant fuzzy averaging (HFA) operator:

$$
\operatorname{HFA}\left(h_{1}, h_{2}, \ldots, h_{\mathrm{n}}\right)=\bigoplus_{j=1}^{n}\left(\frac{1}{n} h_{j}\right)=\bigcup_{\gamma_{1} \in h_{1}, \gamma_{2} \in h_{2}, \ldots, \gamma_{n} \in h_{n}}\left\{1-\prod_{j=1}^{n}\left(1-\gamma_{j}\right)^{1 / n}\right\}
$$

Definition 5. Let $h_{j}(\mathrm{j}=1,2, \ldots, \mathrm{n})$ be a collection of HFSs. A hesitant fuzzy weighted geometric (HFWG) operator is a mapping $H n \rightarrow H$ such that

$$
\operatorname{HFWG}\left(h_{1}, h_{2}, \ldots, h_{\mathrm{n}}\right)=\bigoplus_{j=1}^{n}\left(h_{j}^{w_{j}}\right)=\bigcup_{\gamma_{1} \in h_{1}, \gamma_{2} \in h_{2}, \ldots, \gamma_{n} \in h_{n}}\left\{\prod_{j=1}^{n} \gamma_{j}^{w_{j}}\right\},
$$

where $w=\left(w_{1}, w_{2}, \ldots, w_{n}\right)^{\top}$ is the weight vector of $h_{j}(j=1,2, \ldots, \mathrm{n})$ with $0 \leq w_{j} \leq 1(j=1$, $2, \ldots, n)$ and $\sum_{i=1}^{n} w_{j}=1$.

When $w=(1 / n, 1 / n, \ldots, 1 / n)^{\top}$, the HFWG operator will be reduced to the hesitant fuzzy geometric (HFG) operator:

$$
\operatorname{HFG}\left(h_{1}, h_{2}, \ldots, h_{\mathrm{n}}\right)=\bigoplus_{j=1}^{n}\left(h_{j}^{1 / n}\right)=\bigcup_{\gamma_{1} \in h_{1}, \gamma_{2} \in h_{2}, \ldots, \gamma_{n} \in h_{n}}\left\{\prod_{j=1}^{n} \gamma_{j}^{1 / n}\right\}
$$




\section{The New Assessment Model}

As discussed in Section 1, it is important to construct a new assessment framework with hesitant fuzzy information, in order to help regional sustainable development related to new energy.

Firstly, this paper develops an assessment model of new energy in regional sustainable development based on the existing studies illustrated in Figure 1. Based on this assessment model, it can propose a new method with hesitant fuzzy sets to form a MADM procedure.

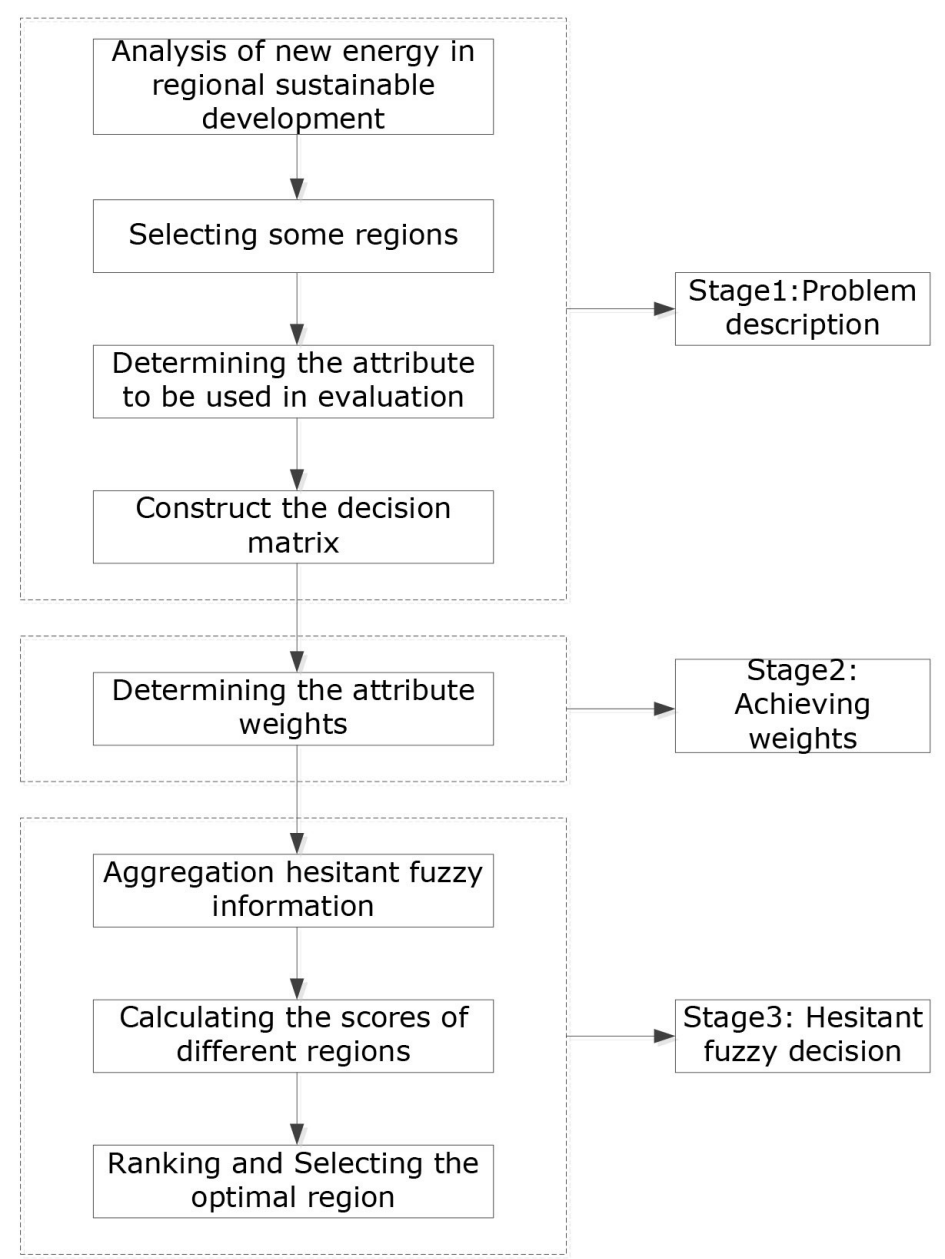

Figure 1. An assessment model of new energy in regional sustainable development

\subsection{The Improved Algorithm}

It needs to compare different assessment results by score function after aggregating hesitant fuzzy information. 
Definition 6. (Xu \& Xia, 2011). Let $h$ be a HFN. The score function of $h$ can be obtained as follow:

$$
\mathbf{S}(h)=\frac{1}{l_{h}} \sum_{\gamma \in h} \gamma,
$$

where $I_{h}$ denotes the number of the elements in $h$.

Definition 7. (Xu \& Xia, 2011). For two HFN $h_{1}$ and $h_{2}$, we have if $\mathrm{S}\left(h_{1}\right)>\mathrm{S}\left(h_{2}\right)$, then $h_{1}$ is better than or preferred to $h_{2}$, denoted by $h_{1} \succ h_{2}$; if $\mathrm{S}\left(h_{1}\right)=\mathrm{S}\left(h_{2}\right)$, then $h_{1}$ is indifferent to $h_{2}$, denoted by $h_{1} \sim h_{2}$;

if $\mathrm{S}\left(h_{1}\right)<\mathrm{S}\left(h_{2}\right)$, then $h_{1}$ is worse than or less preferred to $h_{2}$, denoted by $h_{1} \prec h_{2}$.

In hesitant fuzzy MADM, score function is used to compare the alternatives. However, such score function cannot work in some situations. For example, given three hesitant fuzzy numbers $h_{1}=\{0.1,0.9\}, h_{2}=\{0.5\}, h_{3}=\{0.3,0.5,0.7\}$, they can have the same score 0.5. Therefore, the optimal cannot be got based on the mean score function. In addition, this paper introduces the idea of variance to form a new score function to measure the deviation of hesitant fuzzy elements.

Definition 8. Let $h$ be a HFN. The score function of $h$ is defined as follow:

$$
\mathrm{S}(\mathrm{h})=\bar{\gamma} \cdot\left(1-\frac{\sigma}{\sqrt{n}}\right)
$$

Where $\bar{\gamma}=\frac{\sum_{i=1}^{n} \gamma_{i}}{n}$ and $\sigma(\gamma)=\sqrt{\frac{\sum_{i=1}^{n}\left(\gamma_{i}-\bar{\gamma}\right)^{2}}{n}}$ such that $0<\gamma_{i} \leq 1$.

Example 1. Given two hesitant fuzzy numbers $h_{1}=\{0.1,0.9\}, h_{2}=\{0.5\}$ and $h_{3}=\{0.3,0.5$, $0.7\}$, their scores can be calculated:

$\mathrm{S}(\mathrm{h} 1)=0.5 \cdot(0.1+0.9) \cdot\left(1-\sqrt{\left((0.1-0.5)^{2}+(0.9-0.5)^{2}\right) / 2}\right)=0.3$,

$S(h 2)=0.5$,

$\mathrm{S}(\mathrm{h} 3)=(0.3+0.5+0.7) / 3 \cdot\left(1-\sqrt{\left((0.3-0.5)^{2}+(0.5-0.5)^{2}+(0.7-0.5)^{2}\right) / 3}\right)=0.418$.

Obviously, the results are different from the former. From a point of practical application, variance is an important factor which should be considered. The score function with variance can reflect the meaning of hesitant fuzzy number better. Then, this paper will use the new 
score function to compare the alternatives in the assessment model of new energy in region sustainable development.

\subsection{The Procedure of Proposed Model}

According to the assessment model, this paper proposes a procedure to solve this MADM problem, and attribute values take the form of hesitant fuzzy numbers. The procedure is shown as follows:

Step 1. For a MADM problem, it constructs the decision matrix $D=\left[\tilde{h}_{i j}\right]_{m^{\prime} n^{\prime}}$ where all the arguments $\tilde{h}_{i j}(i=1,2, \ldots, m ; j=1,2, \ldots, n)$ are HFNs, given by the decision maker. As for every alternative $A_{i}(\mathrm{i}=1,2, \ldots, m)$, the decision maker is invited to express evaluation or preference according to each attribute $C_{j}(j=1,2, \ldots, n)$ by a hesitant fuzzy number $h_{i j}(i=1$, $2, \ldots, m ; j=1,2, \ldots, n)$ and specifies the relative weights of the $\mathrm{n}$ attributes denoted as $w=\left(w_{1}, w_{2}, \ldots, w_{n}\right)^{\top}$ with $0 \leq w_{j} \leq 1(j=1,2, \ldots, \mathrm{n})$ and $\sum_{i=1}^{n} w_{j}=1$. Then it can obtain a decision making matrix as follow:

$$
D_{m \times n}=\left[\begin{array}{cccc}
\tilde{h}_{11} & \tilde{h}_{12} & \cdots & \tilde{h}_{1 n} \\
\tilde{h}_{21} & \tilde{h}_{22} & \cdots & \tilde{h}_{2 n} \\
\vdots & \vdots & \ddots & \vdots \\
\tilde{h}_{m 1} & \tilde{h}_{m 2} & \cdots & \tilde{h}_{m n}
\end{array}\right]
$$

Step 2. The hesitant fuzzy weighted averaging (HFWA) operator denoted as Equation 9 or the hesitant fuzzy weighted geometric (HFWG) operator denoted as Equation 11 are introduced to aggregate the hesitant fuzzy assessments. Then, the aggregated hesitant fuzzy numbers represent the alternative in MADM.

Step 3. The new score function proposed in Definition 8 is used to compare the alternative in decision making matrix. It can calculate the scores of the aggregated hesitant fuzzy numbers.

Step 4. Through different scores of alternative, the rank-order can be obtained using Definition 7. Then, we can select optimal alternative by the largest score.

Step 5. End. 


\section{A Case Study}

In this section, this paper utilizes the proposed method to evaluate this assessment framework with hesitant fuzzy information.

As mentioned in Section 1, new energy had been important for humans since the beginning of civilization. Many centuries ago, mankind was already utilizing the clearly visible power of water for working, as was also the case with wind. Now, new energy appears to be the important driving force to promote regional sustainable development.

To realize the effective regional sustainable development, our research institute takes on a project supported by a government office. The director of our project is invited to be the decision maker. As one of main tasks in the project, we try to help the decision maker select optimal region. The decision maker chooses four regions as the alternatives including Beijing $\left(A_{1}\right)$, Shanghai $\left(A_{2}\right)$, Shenzhen $\left(A_{3}\right)$, Hongkong $\left(A_{4}\right)$ from China. Based on the existing studies, the decision maker identifies five attributes $C_{1}, C_{2}, C_{3}, C_{4}, C_{5}$, which are demonstrated in Table 1.

\begin{tabular}{|c|l|}
\hline Attributes & Explanation \\
\hline $\mathbf{C}_{1}$ & Energy security \\
\hline $\mathbf{C}_{2}$ & Social benefits \\
\hline $\mathbf{C}_{3}$ & Economic benefits \\
\hline $\mathbf{C}_{4}$ & Energy Technological benefits \\
\hline $\mathrm{C}_{5}$ & Energy environmental benefits \\
\hline
\end{tabular}

Table 1. Description of the Seven Attributes

So the four experts are invited to express their preferences. Firstly, they give the weight vector of these five attribute denoted as $w=(0.2,0.1,0.3,0.25,0.15)^{T}$; Secondly, they give their preference of every region on each attribute respectively; At last, the decision maker combines the opinions of these experts to provide a hesitant fuzzy decision matrix $D=\left[\tilde{h}_{i j}\right]_{4^{\prime} 5}$, which is illustrated in Table 2.

\begin{tabular}{|c|c|c|c|c|}
\hline & $\mathbf{A}_{1}$ & $\mathbf{A}_{2}$ & $\mathbf{A}_{3}$ & $\mathbf{A}_{4}$ \\
\hline $\mathbf{C}_{1}$ & $\{0.1,0.2,0.5\}$ & $\{0.4,0.8\}$ & $\{0.3,0.6,0.8\}$ & $\{0.7,0.8\}$ \\
\hline $\mathbf{C}_{2}$ & $\{0.2,0.3\}$ & $\{0.4,0.5,0.6\}$ & $\{0.2,0.4\}$ & $\{0.5,0.6\}$ \\
\hline $\mathbf{C}_{3}$ & $\{0.1,0.3,0.5\}$ & $\{0.2,0.3,0.7,0.8\}$ & $\{0.1,0.2,0.3\}$ & $\{0.4,0.5,0.6\}$ \\
\hline $\mathbf{C}_{4}$ & $\{0.2,0.6\}$ & $\{0.4,0.5,0.6\}$ & $\{0.2,0.3,0.4\}$ & $\{0.3,0.4,0.5\}$ \\
\hline$C_{5}$ & $\{0.1,0.3\}$ & $\{0.3,0.4,0.5\}$ & $\{0.2,0.3,0.6\}$ & $\{0.4,0.5,0.8\}$ \\
\hline
\end{tabular}

Table 2. Original Hesitant Fuzzy Decision Matrix 
Based on Section 2, we can get the conclusion that the decision maker is risk-neutral via interviewing with him, and $\eta=1 / 2$, so the normal decision matrix can be obtained. Owing to the limited length of the article, it is omitted.

As mentioned in Definition 4, the hesitant fuzzy assessments can be aggregated through the hesitant fuzzy weighted averaging (HFWA) operator, which are denoted as

$A 1=\{0.1773,0.1866,0.2102,0.2320,0.2814,0.2929,0.3218,0.3324,03486,0.3585,0.4453,0.45$ $51,0.4649 .0 .5224 .0 .5345 .0 .5775 .0 .6025 .0 .6255\}$;

$A 2=\{0.3574,0.3769,0.3770,0.4275,0.4370,0.4550,0.5218,0.5223,0.5224,0.534$, $0.545,0.578,0.5831,0.5967,0.6034,0.6211,0.6345,0.6457,0.6554,0.6558\}$;

$A 3=\{0.2135,0.2215,0.2258,0.2345,0.2375,0.2450,0.2540,0.2830,0.3201,0.3451,0.3870,0.39$ $40,0.4451,0.4568,0.4670,0.5176,0.5270,0.5357,0.5450,0.5527,0.5724,0.5871,0.5975,0.606$ $4,0.6148,0.6154,0.6246,0.6275,0.6378,0.6534,0.6578\}$;

$A 4=\{0.4567,0.5133,0.5155,0.5256,0.5358,0.5450,0.5565,0.5840,0.5849,0.5882,0.5994,0.61$ $01,0.6238,0.6340,0.7052,0.7065,0.7272,0.7546,0.7647,0.7741\}$.

Based on Sections 7 and 8, it can obtain the scores of each alternative, which are showed in Table 3.

\begin{tabular}{|l|c|c|}
\hline & Score & Rank \\
\hline $\mathbf{A}_{1}$ & 0.2564 & 4 \\
\hline $\mathbf{A}_{2}$ & 0.4557 & 2 \\
\hline $\mathbf{A}_{3}$ & 0.3388 & 3 \\
\hline $\mathbf{A}_{4}$ & 0.5226 & 1 \\
\hline
\end{tabular}

Table 3. Scores and Rank-order

In Table 3, the rank-order is demonstrated as $A_{4} \succ A_{2} \succ A_{3} \succ A_{1}$. It is easy to select that Hong kong as $\mathrm{A}_{4}$, and it is the optimal region, in which, new energy can help to realize the regional sustainable development. So the future study is to analysis the advantage of new energy development in Hong kong.

This paper presents hesitant fuzzy sets to solve the assessment issue of new energy in regional sustainable development. Owing to the drawback of existing hesitant fuzzy score function, it defines a new score function, in which, both mean and variance are considered. Meanwhile, the basic operator such as hesitant fuzzy weighted averaging operator and hesitant fuzzy weighted geometric operator are introduced to integrate the hesitant fuzzy information. The research can fill the gaps for the assessment framework of new energy in regional 
sustainable development. So this paper is of practical value in real life, which is the application of some techniques.

\section{Conclusions}

More and more researchers had focused on the new energy of regional sustainable development, especially assessment issue. However, fuzzy environment had been paid little attention in existing studies. Because of the inherent vagueness of human preferences as well as the objects being fuzzy and uncertain, the attributes involved in decision making problems are not always expressed in real numbers, and fuzzy values is an effective way to solve this kind of problem, such as hesitant fuzzy values. So this paper introduces hesitant fuzzy sets to solve the assessment issue of new energy in regional sustainable development. Owing to the drawback of existing hesitant fuzzy score function, it defines a new score function, in which, both mean and variance are considered. Based on the hesitant fuzzy weighted averaging (HFWA) operator and the new score function, it constructs an assessment framework of new energy. What is more, an illustrative example is carried out to verify the reliability of the proposed method.

Although the method can be used to evaluate the new energy in regional sustainable development, it cannot solve the problems with many experts. In the future, this paper will further analysis the advantage of new energy development in Hong Kong and extend the method to solve group decision making problems.

\section{References}

Afgan, N.H. \& Carvalho, M.G. (2008). Sustainability assessment of a hybrid energy system. Energy Policy, 36, 2903-2910. http://dx.doi.org/10.1016/j.enpol.2008.03.040

Bilgen, S., Keles, S., Kaygusuz, A., Sari, A., \& Kaygusuz, K. (2008). Global warming and renewable energy sources for sustainable development: A case study in Turkey. Renewable and Sustainable Energy Reviews, 12, 372-396. http://dx.doi.org/10.1016/j.rser.2006.07.016

Carrera, D.G. \& Mack, A. (2010). Sustainability assessment of energy technologies via social indicators: Results of a survey among European energy experts. Energy Policy, 38, 1030-1039. http://dx.doi.org/10.1016/j.enpol.2009.10.055

Dubois, D., \& Prade, H. (1985). A review of fuzzy sets aggregation connectives. Information Science, 36, 85-121. http://dx.doi.org/10.1016/0020-0255(85)90027-1 
Evans, A., Strezon, V., \& Evans, T.J. (2009). Assessment of sustainability indicators for renewable energy technologies. Renewable and Sustainable Energy Reviews, 13, 1082-1088. http://dx.doi.org/10.1016/j.rser.2008.03.008

Hawila, D., Mondal, M., Kennedy, S., \& Mezher, T. (2014). Renewable energy readiness assessment for North African Countries. Renewable and Sustainable Energy Reviews, 33, 128-140. http://dx.doi.org/10.1016/j.rser.2014.01.066

Kemmler, A., \& Spreng, D. (2007). Energy indicators for tracking sustainability in developing countries. Energy Policy, 35, 2466-2480. http://dx.doi.org/10.1016/j.enpol.2006.09.006

Krupa, J., \& Burch, S. (2011). A new energy future for South Africa: The political ecology of South African renewable energy. Energy Policy, 39, 6254-6261.

http://dx.doi.org/10.1016/j.enpol.2011.07.024

Omer, A.M. (2008). Energy, environment and sustainable development. Renewable and Sustainable Energy Reviews, 12, 2265-2300. http://dx.doi.org/10.1016/j.rser.2007.05.001

Pang, X., Mortberg, U., \& Brown, N. (2014). Energy models from a strategic environmental assessment perspective in an EU context-What is missing concerning renewables? Renewable and Sustainable Energy Reviews, 33, 353-362. http://dx.doi.org/10.1016/j.rser.2014.02.005

Sahir, M.H., \& Qureshi, A.H. (2008). Assessment of new and renewable energy resources potential and identification of barriers to their significant utilization in Pakistan. Renewable and Sustainable Energy Reviews, 12, 290-298. http://dx.doi.org/10.1016/j.rser.2006.07.002

Singh, R.K., Murty, H.R., Gupta, S.K., \& Dikshit, A.K. (2009). An overview of sustainability assessment methodologies. Ecological Indicators, 9, 189-212.

http://dx.doi.org/10.1016/j.ecolind.2008.05.011

Torra, V. (2010). Hesitant fuzzy sets. International Journal of Intelligent Systems, 25(6), 225-235. http://dx.doi.org/10.1002/int.20418

Torra, V., \& Narukawa, Y. (2009). On hesitant fuzzy sets and decision. 2009 IEEE International Conference on Fuzzy Systems, 3, 1378-1382. http://dx.doi.org/10.1109/FUZZY.2009.5276884

Valochi, M., Juliano, J., \& Schurr, A. (2014). Switching Perspectives: Creating new business model for a changing world of energy. Smart Grid Applications and Developments Green Energy and Technology, 165-182. http://dx.doi.org/10.1007/978-1-4471-6281-0_9

Wei, G.W. (2012). Hesitant fuzzy prioritized operators and their application to multi attribute decision making. Knowledge-Based Systems, 31, 176-182.

http://dx.doi.org/10.1016/j.knosys.2012.03.011 
Xia, M.M., \& Xu, Z.S. (2011). Hesitant fuzzy information aggregation in decision making. International Journal of Approximate Reasoning, 52(3), 395-407.

http://dx.doi.org/10.1016/j.ijar.2010.09.002

Xu, Z.S., \& Xia, M.M. (2011). Distance and similarity measures for hesitant fuzzy sets. Information Sciences, 181, 2128-2138. http://dx.doi.org/10.1016/j.ins.2011.01.028

Xu, Z.S., \& Zhang. X.L. (2013). Hesitant fuzzy multi-attribute decision making based on TOPSIS with incomplete weight information. Knowledge-Based Systems, 52, 53-64. http://dx.doi.org/10.1016/j.knosys.2013.05.011

Zadeh, L.A. (1965). Fuzzy sets. Information and Control, 8, 338-356.

http://dx.doi.org/10.1016/S0019-9958(65)90241-X

Zimmermann, H.J. (1985). Fuzzy Set Theory and Its Applications. Kluwer Academic Publishers, Dordrecht. http://dx.doi.org/10.1007/978-94-015-7153-1

Journal of Industrial Engineering and Management, 2014 (www.jiem.org)

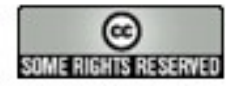

Article's contents are provided on a Attribution-Non Commercial 3.0 Creative commons license. Readers are allowed to copy, distribute and communicate article's contents, provided the author's and Journal of Industrial Engineering and Management's names are included. It must not be used for commercial purposes. To see the complete license contents, please visit http://creativecommons.org/licenses/by-nc/3.0/. 